\title{
New reference ranges for interpreting forced expiratory manoeuvres in infants and implications for clinical interpretation: a multicentre collaboration
}

\author{
Sooky Lum, ${ }^{1}$ Vassiliki Bountziouka, ${ }^{1}$ Angela Wade, ${ }^{2}$ Ah-Fong Hoo, ${ }^{1,3}$ Jane Kirkby, ${ }^{1,3}$ \\ Antonio Moreno-Galdo, ${ }^{4}$ Ines de Mir, ${ }^{4}$ Olaia Sardon-Prado, ${ }^{5,6}$ Paula Corcuera-Elosegui, ${ }^{5}$ \\ Joerg Mattes, 7,8 Luis Miguel Borrego, ${ }^{9,10}$ Gwyneth Davies, 1,3 Janet Stocks $^{1}$
}

\section{- Additional material is published online only. To view, please visit the journal online (http://dx.doi.org/10.1136/ thoraxjnl-2015-207278) \\ For numbered affiliations see end of article. \\ Correspondence to Dr Sooky Lum, Respiratory, Critical Care \& Anaesthesia Section in IIIP Programme, UCL, Institute of Child Health, 30 Guilford Street, London WC1N 1EH, UK; \\ s.lum@ucl.ac.uk}

Received 7 May 2015 Revised 23 July 2015 Accepted 29 September 2015 Published Online First 2 November 2015

\section{SLinked}

- http://dx.doi.org/10.1136/ thoraxinl-2015-207911

\section{CrossMark}

\section{To cite: Lum $S$,}

Bountziouka V, Wade A

et al. Thorax 2016;71:

276-283.

\section{ABSTRACT}

The raised volume rapid thoracoabdominal compression (RVRTC) technique is commonly used to obtain full forced expiratory manoeuvres from infants, but reference equations derived from 'in-house' equipment have been shown to be inappropriate for current commercially available devices.

Aim To explore the impact of equipment differences on RVRTC outcomes, derive robust equipment-specific RVRTC reference ranges and investigate their potential clinical impact on data interpretation.

Method RVRTC data from healthy subjects using Jaeger BabyBody or the 'Respiratory Analysis Software Program, RASP' systems were collated from four centres internationally. Data were excluded if gestational age $<37$ weeks or birth weight $<2.5 \mathrm{~kg}$. Reference equations for RVRTC outcomes were constructed using the LMS (lambda-mu-sigma) method, and compared with published equations using data from newborn screened infants with cystic fibrosis (CF).

Results RVRTC data from 429 healthy infants (50.3\% boys; 88\% white infants) on 639 occasions aged 4118 weeks were available. When plotted against length, flows were significantly higher with RASP than Jaeger, requiring construction of separate equipment-specific regression equations. When comparing results derived from the new equations with those from widely used published equations based on different equipments, discrepancies in forced expiratory volumes and flows of up to $2.5 \mathrm{z}$-scores were observed, the magnitude of which increased with age. According to published equations, 25\% of infants with CF fell below the 95\% limits of normal for $\mathrm{FEV}_{0.5}$, compared with only $10 \%$ when using the new equations.

Conclusions Use of equipment-specific prediction equations for RVRTC outcomes will enhance interpretation of infant lung function results; particularly during longitudinal follow-up.

\section{INTRODUCTION}

During the past 20 years, the raised volume rapid thoracoabdominal compression (RVRTC) technique for obtaining forced expiratory flow volume (FEFV) manoeuvres has been shown to discriminate clearly between healthy infants and those with lung disease. ${ }^{1-8}$ However, replacement of 'in-house' infant lung function (ILF) equipment by

\section{Key messages}

What is the key question?

- To what extent are results derived from the raised volume technique for assessing forced expiratory manoeuvres in infants misinterpreted due to use of inappropriate reference equations?

\section{What is the bottom line?}

- Equipment-specific reference equations are essential for accurate interpretation of lung function in early life since use of equations derived from different infant lung function devices may lead to significant misclassification of lung disease.

\section{Why read on?}

- The extent of bias that may be introduced by using reference ranges derived from different equipment emphasises the need to use equipment-specific reference ranges when interpreting infant lung function results to permit appropriate tracking of lung health across the early years.

commercial devices has complicated data interpretation. In a recent survey on the role of ILF tests in clinical practice, $77 \%$ of responders were using RVRTC, most of whom interpreted results using reference data published in $2000^{9}$ prior to introduction of commercial RVRTC devices. ${ }^{10}$ We have previously shown that prediction equations for RVRTC derived from 'in-house' equipment are inappropriate for commercially available devices, and although an interim correction factor was proposed, ${ }^{11}$ this was only based on a limited dataset.

During the past 5 years, the increasing availability of RVRTC data from healthy infants studied using commercial equipment in various centres worldwide, together with development of sophisticated statistical modelling techniques has provided the opportunity to improve interpretation of ILF results by developing more robust equipmentspecific reference equations. 
The primary aims of this study were to:

1. investigate the extent to which published equations, ${ }^{9}$ or a proposed interim correction factor ${ }^{11}$ fit data collected using the only currently available commercial equipment for assessing RVRTC (Jaeger Masterscreen BabyBody; Carefusion, Hoechberg, Germany);

2. collate available RVRTC data from centres using Jaeger equipment and the same protocols and to derive equipmentspecific reference ranges for RVRTC outcomes;

3. investigate the clinical implications of implementing the 'Jaeger-specific' reference equations in infants with cystic fibrosis (CF).

To facilitate interpretation of longitudinal lung function (LF) data throughout childhood and adolescence, our secondary aim was to apply similar methodology to develop separate reference equations for use in infants previously studied with 'in-house' equipment and the Respiratory Analysis Software Program (RASP), as used in various studies prior to 2002.

\section{METHODS}

An initial assessment of potentially available RVRTC data from healthy infants was undertaken by the American Thoracic Society/European Respiratory Society (ATS/ERS) Infant and Preschool LF testing Task Force in 2013. Collaborators were subsequently identified as those indicating willingness to participate once data collection for specific studies had been completed.

RVRTC data from healthy infants and children $<2.5$ years of age collected using the Jaeger BabyBody were available from four specialised paediatric centres in the UK, Spain, Portugal and Australia as described previously. ${ }^{5} \quad 8 \quad 12-14$ Similar data collected using the RASP system were also available from the UK centre. $^{3} 15$ Regrettably, although RVRTC data collection using the nSpire IPL system in healthy infants is currently in progress, investigators were not in a position to release these data at time of collation, and this device is no longer commercially available.

The reference population comprised healthy full-term ( $\geq 37$ weeks' gestational age and birth weight $\geq 2.5 \mathrm{~kg}$ ) infants without congenital abnormalities or respiratory compromise (ie, no current respiratory morbidity or history of respiratory illness requiring hospitalisation) recruited to epidemiological studies or as controls for clinical research. ${ }^{3-5} \quad 81^{12-15}$ A population of infants diagnosed with CF by newborn screening without significant comorbidity recruited to recent clinical research studies $^{13} 16$ was used to investigate the impact of using different equations to interpret results. Local research ethics committee approval was granted for each study (see online supplementary material for details) and written informed parental consent obtained for all infants.

\section{Equipment and study protocol}

LF tests were undertaken at least 3 weeks after any respiratory illness. Data were collected during quiet sleep, after oral sedation with chloral hydrate $(50-100 \mathrm{mg} / \mathrm{kg}$ depending on age). RVRTC data collected using Jaeger were obtained using identical study protocols for data collection, analysis and quality control (QC). ${ }^{17}$ RVRTC data using the 'in-house' RASP equipment and identical protocols were collated from studies undertaken in London prior to switching to the Jaeger equipment in 2002. RVRTC data collection and analyses were performed in accordance with ATS/ERS guidelines. ${ }^{18}$ Researchers from all centres were trained by the ILF team (AFH, SL and JS) in London, with inter-laboratory visits to observe tests in progress and independent over-read of results to ensure QC.
Detailed descriptions of data collection and analysis using the Jaeger equipment have been published. ${ }^{17}$ In brief, RVRTC was performed from an inflation pressure of $30 \mathrm{~cm} \mathrm{H}_{2} \mathrm{O}$, the manoeuvre being repeated until three acceptable and repeatable FEFV curves were obtained. Forced expired volume in $0.5 \mathrm{~s}$ $\left(\mathrm{FEV}_{0.5}\right)$, FVC, $\mathrm{FEV}_{0.5} / \mathrm{FVC}$, forced expiratory flow when $75 \%$ FVC had been expired $\left(\mathrm{FEF}_{75}\right)$ and $\mathrm{FEF}$ between $25 \%$ and $75 \%$ FVC $\left(\mathrm{FEF}_{25-75}\right)$ were reported from the 'best' raised volume curve. The latter was defined as the technically acceptable FEFV curve with the highest sum of FVC and $\mathrm{FEV}_{0.5} \cdot{ }^{18}$

\section{Statistical analysis}

Descriptive characteristics are shown as mean (SD) or median (range) for continuous variables and as $\mathrm{n}(\%)$ for categorical ones (IBM SPSS Statistics V.22). Multiple fractional polynomials ${ }^{19}$ were used to identify the most suitable transformation of the independent variables (ie, height, weight, age) when modelling LF outcomes to achieve normality of the residuals. The 'nlme' package in R (V.3.1-117) was used to check the models and the assumptions for the residuals distribution using the selected multiple fractional polynomial transformations, taking into account repeated measurements in individuals nested within centres by applying a random intercept model. Reference equations for RVRTC outcomes were then constructed as described previously ${ }^{20} 21$ using the LMS (lambda-mu-sigma) method $^{22}$ and the best polynomial combination. This method is an extension of regression analysis that includes three components: (1) skewness (lambda, L), which models the departure of variables from normality using a Box-Cox transformation; (2) median $(\mu, M)$ or predicted value; and (3) coefficient of variation (sigma, $S$ ), which models the spread of values around the median and adjusts for any non-uniform dispersion. The three quantities are allowed to change with length and/or age, to reflect changes in the distribution as children grow. The L, M and $S$ coefficients are combined algebraically to convert individual observations to $\mathrm{z}$-scores: $\mathrm{z}$-score $=\left((\text { measurement } / \mathrm{M})^{\mathrm{L}}-1\right)$ / $(\mathrm{L} \times \mathrm{S}) .^{22}$ The LMS method was applied using the GAMLSS package in $\mathrm{R}^{23}$ Goodness of fit was assessed using the Schwarz Bayesian criterion, which compares consecutive models directly while adjusting for increased complexity to determine the simplest model with best fit. ${ }^{24}$ See online supplementary material for further details. In addition to age, body size and sex, the potential impact of ethnicity and tobacco smoke exposure on RVRTC outcomes was also examined.

To examine the potential clinical implications of using different equations, RVRTC data from infants with CF diagnosed by newborn screening that had been collected using the Jaeger equipment were expressed as z-scores using the new equipmentspecific prediction equations and results compared with those derived from published reference equations ('Jones' equations) ${ }^{9}$ and after applying a previously proposed interim correction factor. $^{11}$

\section{RESULTS}

\section{Healthy infants}

RVRTC data from 431 healthy term infants on 653 test occasions were collated from the four centres. RASP data were collected between 1997 and 2002, and Jaeger data between 2001 and 2014. After 14 exclusions (figure 1), data were available from 429 infants (50\% boys; $88 \%$ white infants) on 639 test occasions (age: $3.8-117.8$ weeks; weight: $3.0-14.8 \mathrm{~kg}$; length: $50.2-$ $92.5 \mathrm{~cm})$. Group characteristics of the reference population according to equipment and centre are summarised in table 1. 


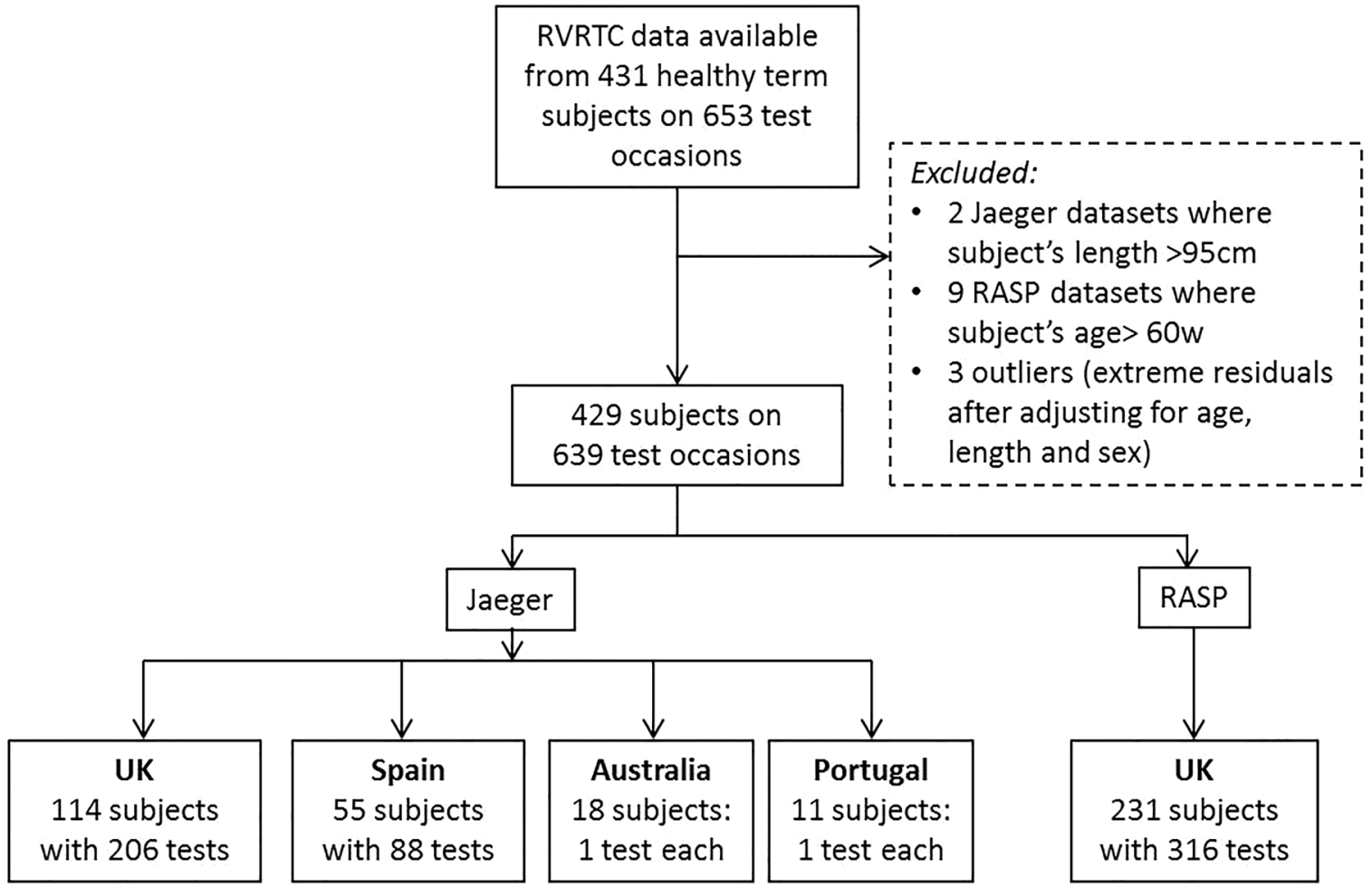

Figure 1 Flowchart illustrating collated FEFV data from four centres. To ensure prediction equations were not biased by distribution, the range of collated data used for deriving the prediction equations were limited to subjects with length $<95 \mathrm{~cm}$ for Jaeger data and age $<60 \mathrm{w}$ for RASP data. FEFV, forced expiratory flow volume; RVRTC, raised volume rapid thoracoabdominal compression; RASP, Respiratory Analysis Software Program.

Jaeger RVRTC data plotted against length showed a positive association between LF and growth with good overlay between centres (figure 2).

\section{Extent to which RVRTC data fit published equations}

When comparing RVRTC data between equipment (RASP vs Jaeger), the spread for LF outcomes, especially $\mathrm{FEF}_{25-75}$, was higher for RASP data and appeared to increase with growth (see online supplementary figure S1). After adjusting for age, height and sex, the Jones equations ${ }^{9}$ provided a reasonable mean fit for the RASP data from healthy term infants and young children but, with the exception of $\mathrm{zFEV}_{0.5} / \mathrm{FVC}$, the spread of data was wider than expected (mean (SD) $\mathrm{zFEV}_{0.5}:-0.24$ (1.32); zFVC:
-0.38 (1.19); $\mathrm{zFEF}_{25-75}:-0.03$ (1.38) z-scores) such that the lower limit of normal would be inappropriate. The Jones equations ${ }^{9}$ were not appropriate for Jaeger data, with LF from healthy infants being significantly lower than expected by an average (SD) of 0.61 (1.09) z-scores for $\mathrm{FEV}_{0.5}, 0.36$ (1.09) z-scores for FVC, 0.31 (1.18) for $\mathrm{FEV}_{0.5} / \mathrm{FVC}$ and 1.13 (1.05) $\mathrm{z}$-scores for $\mathrm{FEF}_{25-75}$. The overestimation of abnormalities among these healthy subjects increased with length (figure 3A) and age (see online supplementary figure S2A).

\section{New equipment-specific RVRTC reference equations}

The Jaeger-specific RVRTC reference equations for infants and young children aged between 4 and 118 weeks, with lengths

Table 1 Group characteristics of reference population according to centre and equipment

\begin{tabular}{|c|c|c|c|c|c|c|}
\hline \multirow{2}{*}{$\begin{array}{l}\text { Equipment } \\
\text { centre }\end{array}$} & \multicolumn{5}{|l|}{ Jaeger } & \multirow{2}{*}{$\begin{array}{l}\text { RASP } \\
\text { London, UK }\end{array}$} \\
\hline & London, UK & Newcastle, Australia & Barcelona-Donostia, Spain & Lisbon, Portugal & ALL & \\
\hline Subjects, $\mathrm{n}$ & 114 & 18 & 55 & 11 & 198 & 231 \\
\hline Boys & $45 \%$ & $61 \%$ & $44 \%$ & $82 \%$ & $48 \%$ & $52 \%$ \\
\hline White infants & $76 \%$ & $83 \%$ & $100 \%$ & $100 \%$ & $84 \%$ & $91 \%$ \\
\hline Test occasions, $\mathrm{n}$ & 206 & 18 & 88 & 11 & 323 & 316 \\
\hline Postnatal age* $(w)$ & $50.7(8-112)$ & $56.4(15-112)$ & $73.2(21-104)$ & $57.9(45-118)$ & $52.2(8-118)$ & $7.7(4-59)$ \\
\hline Length* $(\mathrm{cm})$ & $75.5(54.1-92.5)$ & $76.8(57.2-85.9)$ & $79.0(54-86.8)$ & $78.0(71.5-84.5)$ & $75.9(54-92.5)$ & $57.9(50.2-78.8)$ \\
\hline z-Lengtht & $0.76(0.94)$ & $-0.24(1.29)$ & $0.10(1.17)$ & $-0.04(1.3)$ & $0.50(1.10)$ & $0.25(1.04)$ \\
\hline z-Weight $†$ & $0.32(0.92)$ & $0.20(1.38)$ & $0.14(0.95)$ & $-0.02(0.90)$ & $0.25(0.96)$ & $-0.13(0.92)$ \\
\hline Smoking in pregnancy & $12 \%$ & $22 \%$ & $7 \%$ & $18 \%$ & $12 \%$ & $36 \%$ \\
\hline Postnatal smoking exposure & $15 \%$ & $67 \%$ & $15 \%$ & $36 \%$ & $18 \%$ & $44 \%$ \\
\hline
\end{tabular}



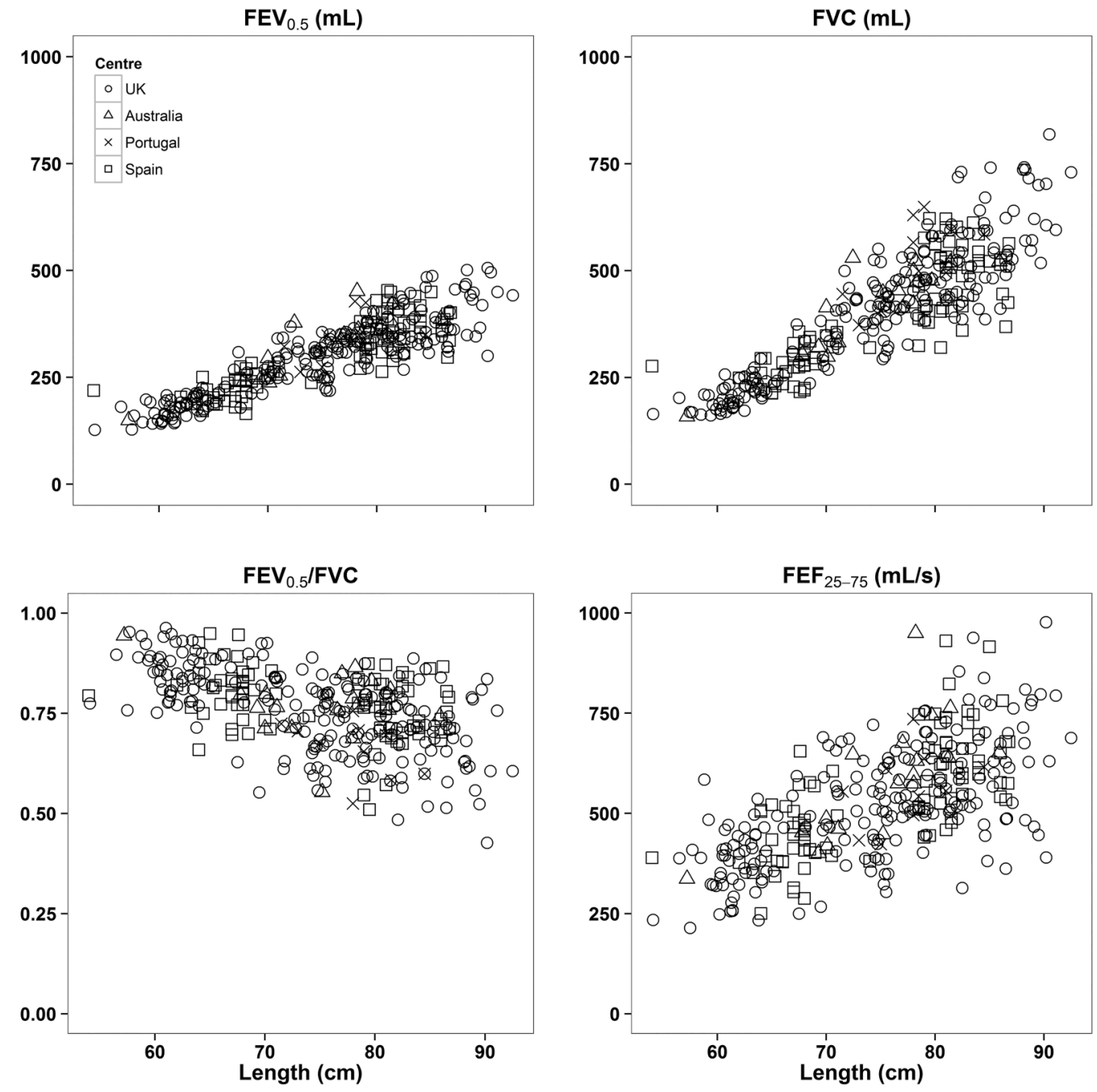

Figure 2 Forced expiratory flow volume (FEFV) data using the Jaeger equipment according to centre. As can be seen, there was good overlay between centres. Further details are presented in the online supplementary figure S4.

between 54 and $92 \mathrm{~cm}$ are given in table 2. The mean (SD) z-scores for all RVRTC outcomes in healthy controls approximated 0 (1) with $95 \%$ of data falling within \pm 1.96 z-scores (figure 3B; see online supplementary figure S2B). Fitted centiles with the corresponding limits of normal are shown in online supplementary figure S3. No significant associations between Jaeger RVRTC outcomes and either ethnicity or tobacco smoke exposure were identified. When modelling was limited to data from white subjects or those not exposed to tobacco smoking, prediction equations were similar to those derived from all data (data not shown). Comparisons of data from the different centres are shown in the online supplementary figure S4.

Prediction equations for RASP data, applicable to infants aged 4-59 weeks and 50-79 $\mathrm{cm}$ are presented in the online supplementary table S1 (see also figure 3C and online supplementary figure S2C). For infants studied using RASP, in whom there was much higher tobacco smoke exposure (see online supplementary table S2), lower flows were observed among those exposed.

\section{Clinical implications of using different RVRTC reference equations when interpreting data from infants with CF} Jaeger RVRTC data were also available from 100 (51\% boys) newborn screened infants and young children with CF, who were studied in London on 233 test occasions between 2009 and 2014 (median (range) age: $50.4 \mathrm{w}$ (8-111). The impact of using inappropriate reference equations for interpreting results is clearly illustrated in figure 4. Reliance on the 'Jones' reference equations ${ }^{9}$ would have led to $57 / 233(24.5 \%)$ tests in CF infants being classified as having 'abnormal' $\mathrm{FEV}_{0.5} \quad(\leq 1.96$ $\mathrm{z}$-scores). However, application of the new Jaeger-specific equations indicated that $58 \%(33 / 57)$ of CF infants with abnormal results according to Jones equations were misclassified. Similarly, of the 41 (18\%) and 83 (36\%) of CF infants identified as having diminished $\mathrm{FVC}$ and $\mathrm{FEF}_{25-75}$ respectively according to Jones' equations, 61\% (25/41) and 69\% (57/83) would have been misclassified. When using the Jones equations, abnormalities in FVC and $\mathrm{FEV}_{0.5}$ were increasingly overestimated with age (figure $5 \mathrm{~A}$ ). Thus both the prevalence and severity of LF abnormalities in CF infants were grossly overestimated when using the Jones equations. While application of the interim correction factor to the Jones equations ${ }^{11}$ tended to slightly overestimate abnormalities in younger infants, they appeared adequate for older subjects (figure 5B).

\section{DISCUSSION}

In this study, we have shown conclusively that published reference data ${ }^{9}$ for RVRTC outcomes which were based on data collected using 'in-house' systems are inappropriate for data 
Figure 3 Forced expiratory flow volume (FEFV) data from healthy infants according to published and new equipment-specific prediction equations. Within a normal population, one would expect $95 \%$ of a healthy population to fall within \pm 1.96 SD or $\mathrm{z}$-scores of predicted values, with only $2.5 \%$ below the lower limit of normal (LLN: $\leq-1.96 \mathrm{z}){ }^{28}$ While this is true for the new equipment-specific equations shown in panels $B$ and $C$, when the Jones equations ${ }^{9}$ are applied to results from healthy infants studied using either the Respiratory Analysis Software Program (RASP) system or Jaeger equipment $(A)$, up to $15 \%$ fell below the LLN depending on outcome.
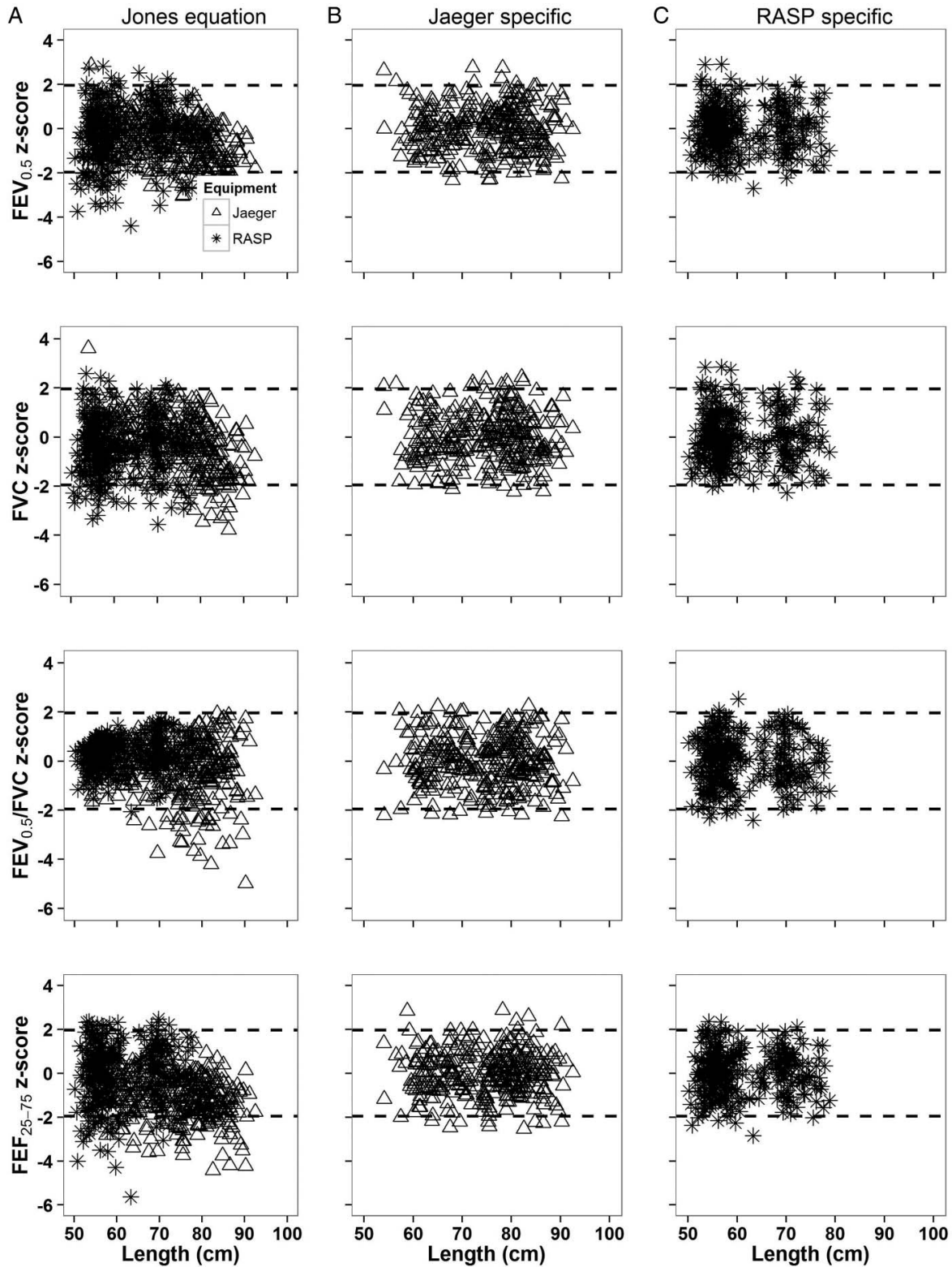

collected using other equipment, whether 'in-house' or commercially available. Since RVRTC is being increasingly used worldwide with Jaeger BabyBody being the only commercial equipment currently available, it is essential to have appropriate and robust equipment-specific reference equations for interpreting data. FEFV data from healthy infants collected using Jaeger equipment were significantly lower than those predicted by the Jones equations, resulting in an overestimation of abnormalities in both health and disease, the magnitude of which increased with age. While adequate for older infants and toddlers, interim efforts to apply an adjustment for equipment-specific differences ${ }^{11}$ also overestimated abnormality in younger infants. Through multicentre collaboration and using sophisticated statistical modelling techniques, we have now developed improved equipment-specific RVRTC reference equations which will enhance interpretation of infant LF results over the first 2 years of life.

\section{Strengths and limitations}

The multicentre collaboration which provided the largest dataset of RVRTC results to date using the same methodology and equipment is one of the main strengths of this study. In addition, the training provided by experienced investigators in London, with independent QC and over-read of data from other centres ensured a high degree of QC and reliability, minimising the chance that the lower flows and volumes from Jaeger were simply due to failure to achieve flow limitation or poor QC.

A potential limitation of the study is the small number of data from two of the sites and the possible bias that could be introduced due to the fact that the Institute of Child Health in London not only provided the majority of data and developed standardised QC criteria but also trained investigators from other centres. Nevertheless, availability of the recently published ILF testing manual ${ }^{17}$ with a step-by-step guide to ILF assessments using Jaeger equipment should facilitate future quality and consistency of such assessments, allowing these new equations to be used reliably to interpret RVRTC data from other centres using the same equipment and QC. There is an urgent need for users of nSpire infant equipment to undertake a similar exercise.

\section{Equipment-specific differences and prediction equations}

As reported previously, possible reasons for the lower flows observed when using Jaeger rather than 'in-house' equipment 
Table 2 Jaeger rapid thoracoabdominal compression (RVRTC) prediction equations

\begin{tabular}{|c|c|}
\hline & Jaeger \\
\hline \multicolumn{2}{|c|}{$\mathrm{FEV}_{0.5}$} \\
\hline M & $\exp (8.8873-25.349 / \sqrt{\text { Length }}-1.668 / \sqrt{\text { Age }})$ \\
\hline L & 1 \\
\hline$S$ & 0.1296 \\
\hline \multicolumn{2}{|l|}{ FVC } \\
\hline M & $\exp (4.6391+0.023 \times$ Length $-2.496 / \sqrt{\text { Age }})$ \\
\hline L & 1 \\
\hline$S$ & $\exp (-1.6217-1.839 / \sqrt{\mathrm{Age}})$ \\
\hline \multicolumn{2}{|c|}{$\mathrm{FEV}_{0.5} / \mathrm{FVC}$} \\
\hline M & $\exp (0.0977-0.0942 \times \mathrm{LN}(\mathrm{Age})-0.0285 \times$ Sex $)$ \\
\hline L & 2.380 \\
\hline$S$ & $\exp (-3.4316+0.3038 \times \mathrm{LN}($ Age $))$ \\
\hline \multicolumn{2}{|c|}{$\mathrm{FEF}_{25-75}$} \\
\hline M & $\exp (7.8253-114.29 /$ Length $-0.064 \times$ Sex $)$ \\
\hline $\mathrm{L}$ & 0.672005 \\
\hline$S$ & 0.2027 \\
\hline \multicolumn{2}{|l|}{$\mathrm{FEF}_{75}$} \\
\hline M & $\exp (7.5205-131.29 /$ Length $-0.0662 \times$ Sex $)$ \\
\hline L & 1 \\
\hline$S$ & 0.2417 \\
\hline
\end{tabular}

include differences in internal algorithms relating to BTPS (Body Temperature and Pressure, Saturated) and volume drift corrections. ${ }^{11}$ It is therefore not surprising that the Jones equations ${ }^{9}$ are inappropriate for interpreting data from current commercial equipment. The overestimation of predicted values according to Jones such that Jaeger results were underestimated, resulted in a progressive overestimation of abnormalities with age (figure 5A). These results emphasise the importance of examining whether potential lung function reference equations are appropriate across the entire age or height range studied and not simply as a group mean. We previously developed an interim correction factor that could be applied to the Jones equations in an attempt to address observed equipment-related differences. ${ }^{11}$ However, due to the relatively few healthy infants studied with the Jaeger device at the time, sample size was unsuitable for complex modelling and hence did not completely solve the problem. Thus although application of the interim correction factors improved the fit for Jaeger data from older infants, they still tended to overestimate abnormalities in younger infants (figure 5B). Reasons for discrepancies in this age group could also relate to the limited number of very young infants included within the original Jones dataset.
Neither the Jones nor the new Jaeger equations should be applied to data collected using the RASP system, prediction equations for which are presented in online supplementary table S1. Although use of such equations will be limited to the relatively small number of centres which used this equipment and software in the past, ${ }^{3}$ their availability will facilitate improved interpretation of longitudinal studies, such as that currently being undertaken in clinically diagnosed children with $\mathrm{CF}^{26}{ }^{27}$ who are now being followed up during adolescence (http://www.ucl.ac.uk/london-cystic-fibrosis/).

\section{Reference population}

As reported previously, ${ }^{9}{ }^{11}$ length and age are major determinants of infant LF, with sex also contributing to the $\mathrm{FEV}_{0.5} / \mathrm{FVC}$ ratio and $\mathrm{FEF}_{\%}$, indicating relatively smaller airway calibre in relation to lung size in boys compared with girls during the first 2 years of life. Ethnic differences in LF in older subjects have been well documented. ${ }^{28}$ However, within the current reference population, ethnicity was not shown to be associated with RVRTC outcomes, possibly due to the limited data from those of non-white, European descent. Results from such subjects must therefore be interpreted cautiously until further ethnicspecific data are available.

In contrast to the approach taken by Jones et $a l,{ }^{9}$ we did not include 'smoking status' in the regression models so that the potential impact of tobacco-smoke exposure can be examined separately. Following successive government strategies to tackle smoking in the UK, ${ }^{29}$ smoking prevalence in London mothers has fallen over the past decade from $\sim 40 \%$ in the $1990 \mathrm{~s}^{15}{ }^{30}$ to around $16 \%$ currently. ${ }^{8}$ The lack of association between tobacco smoke exposure and LF in infants studied using the Jaeger equipment, probably reflects the recent low exposure rates. By contrast, during earlier assessments using the RASP device where a much higher proportion of infants were exposed to household smoking, ${ }^{15}{ }^{30} \mathrm{FEV}_{0.5} / \mathrm{FVC}$ and $\mathrm{FEF}_{25-75}$ were both significantly lower when compared with those not exposed (see online supplementary table S2).

\section{Clinical implications}

The clinical importance of appropriate reference equations for interpreting LF data in older children and adults is well recognised. ${ }^{3132}$ Its relevance to infants and young children is particularly timely given the importance of accurately interpreting outcome in diseases such as CF in the first few years of life in an era when the potential for early disease-modifying treatments is becoming a reality. Understanding which infants have abnormal LF or how change over time occurs within individuals is only possible with appropriate reference data to track lung health accurately. Our results clearly illustrate the potential consequences of using inappropriate reference equations. Despite the well-recognised difficulties, ${ }^{33}$ we have always recruited and
Figure 4 Comparison of forced expiratory flow volume data from newborn screened infants with cystic fibrosis (CF) collected using the Jaeger device when interpreted according to Jones et al and the new Jaeger-specific equations. Data were available from 100 infants with CF on 233 occasions. Solid lines denote the mean value for the group and dotted lines denote the upper and lower limit of the normal range (as defined by $\pm 1.96 z$-scores).
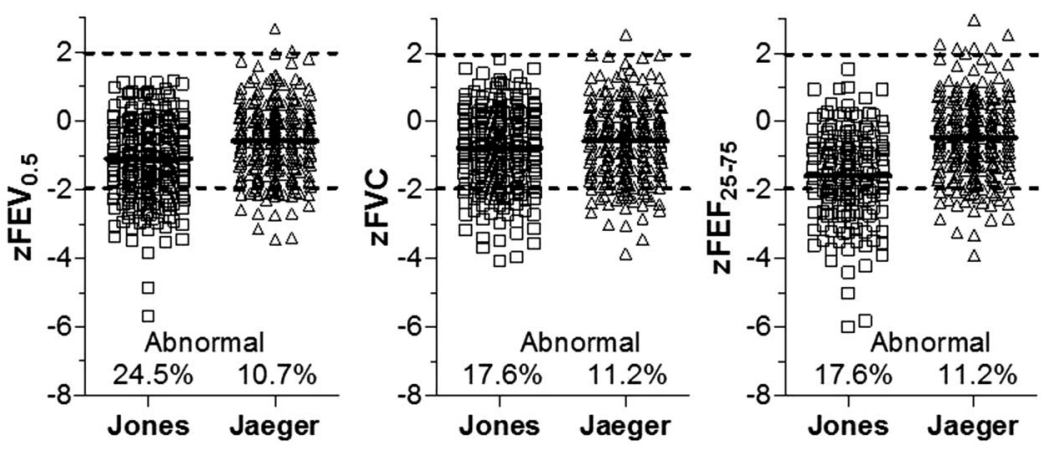

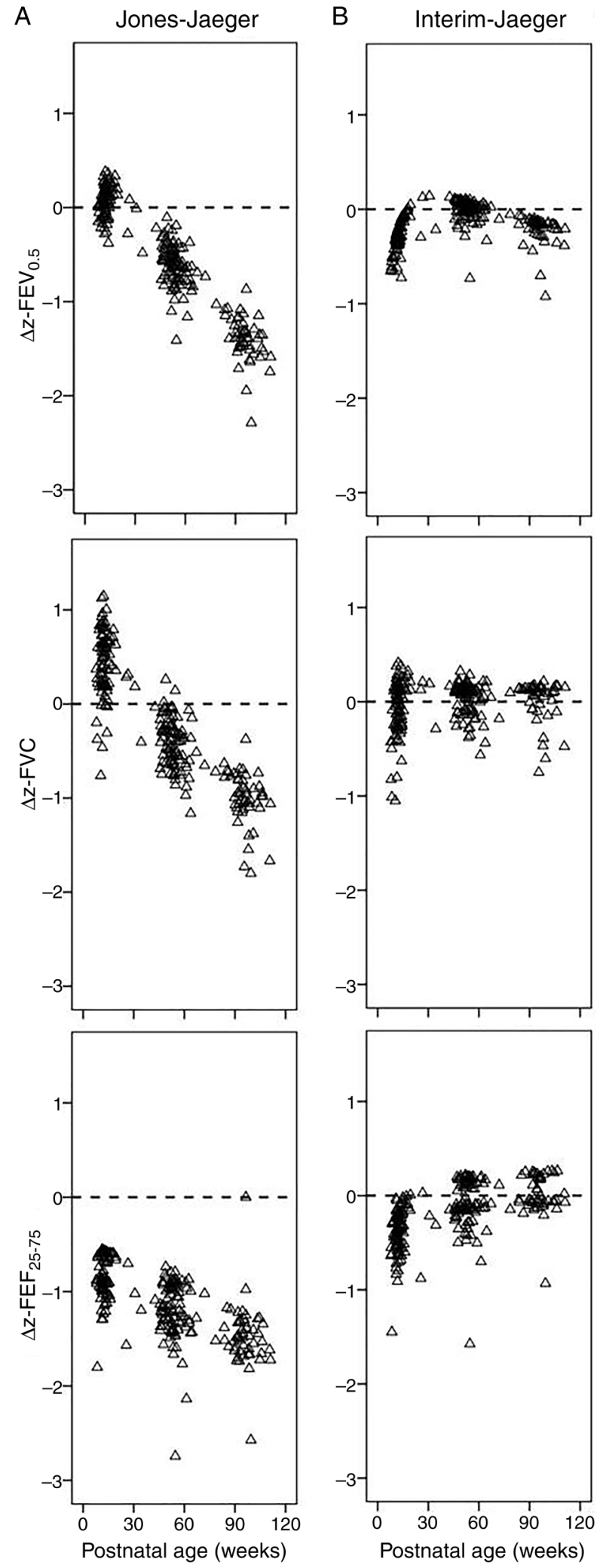

Figure 5 Discrepancies in calculated forced expiratory flow volume (FEFV) z-scores between existing and new reference equations according to subjects' age. Graphs are plotted as the z-score difference $(\Delta \mathrm{z})$ in FEFV outcomes in each infant between results derived from $(A)$ Jones ${ }^{9}$ minus current Jaeger-specific and (B) Interim correction factor applied to Jones ${ }^{11}$ minus new Jaeger-specific reference equations. When using the Jones equations, the relative underestimation of lung function is progressive with age, whereas the interim correction factor ${ }^{11}$ adjusts adequately for infants above $\sim 15$ weeks of age but tends to underestimate results in younger infants. prospectively assessed healthy controls for clinical research projects in order to strengthen interpretation of results. The importance of such an approach is illustrated by our current findings, since without such controls we would have misinterpreted both the prevalence and magnitude of abnormalities among new-born screened infants with CF during the first 2 years of life, as well as the change over time. Despite the shift in z-scores between published and new equipment-specific equations, the magnitude of the difference in $\mathrm{z}$-scores between $\mathrm{CF}$ infants and healthy controls remained similar whether previously published ${ }^{9}{ }^{11}$ or current reference ranges were applied. This confirms recent reports that LF in newborn screened CF infants remains stable or improves during the first 2 years of life, with considerably smaller deficits than previously observed prior to the introduction of newborn screening. ${ }^{13}{ }^{16}$ By contrast, had we relied solely on the original Jones equations without a contemporaneous control group, we would have falsely concluded that LF deteriorates with age in newborn screened infants, with mean $\mathrm{FEV}_{0.5}$ approximating -2 z-scores during the second year of life (figure $5 \mathrm{~A}$ ). We suggest that such scenarios may contribute the significant 'abnormalities' in infant LF outcomes reported by others in the newborn screened CF literature. ${ }^{7}$ Continued use of inappropriate reference equations for longitudinal follow up would result in significant overdiagnosis of abnormal LF, and overestimation of the rate of decline in LF during the first 2 years of life.

\section{CONCLUSIONS AND FUTURE DIRECTIONS}

We have shown that published reference ranges derived from 'in-house' equipment are inappropriate for interpreting RVRTC data collected using other equipment, including the only commercially available system currently available. We present new robust equipment-specific RVRTC prediction equations to improve interpretation of data previously collected using the RASP system as well as current data obtained with the Jaeger device, although further work is required to ascertain whether these are equally applicable to infants who are not of white European descent. As in older subjects, even when adequate reference equations are available, assessment and interpretation of LF in infants should always be undertaken within an appropriate clinical context. Our equipment-specific equations for infant LF testing will improve the ability to track lung health from early life. This should, in turn, ultimately improve our understanding of the evolution of respiratory morbidity in diseases such as CF, and enable an appropriate evaluation of the utility of infant LF testing as an outcome measure in clinical trials.

\section{Author affiliations}

${ }^{1}$ Respiratory, Critical Care \& Anaesthesia section in IIIP Programme, UCL, Institute of Child Health, London, UK

${ }^{2}$ Department of Clinical Epidemiology, Nutrition and Biostatistics Section, UCL, Institute of Child Health, UK

${ }^{3}$ Respiratory Medicine, Great Ormond Street Hospital for Children NHS Foundation Trust, London, UK

${ }^{4}$ Paediatric Pulmonology Unit, Hospital Vall d'Hebron, Universitat Autònoma de Barcelona, Barcelona, Spain

${ }^{5}$ Division of Paediatric Respiratory Medicine, Donostia University Hospital, San Sebastian, Spain

${ }^{6}$ Department of Paediatrics, University of the Basque Country, San Sebastian, Spain ${ }^{7}$ School of Medicine and Public Health, University of Newcastle, Newcastle, Australia ${ }^{8}$ Department of Paediatric Respiratory \& Sleep Medicine, John Hunter Children's Hospital, Newcastle, Australia

${ }^{9}$ Centro de Alergia, CUF Descobertas Hospital, Lisbon, Portugal

${ }^{10}$ CEDOC, NOVA Medical School, Lisbon, Portugal

Acknowledgements We thank the infants and parents participating in the research studies. We also would like to thank Iris Goetz, Georg Hulskamp, Henrik 
Ljungberg, Padmaja Subbarao, Teresa Bandeira, Joanne Chittenden, Amit Gupta, Alicia Bolton, The Thanh Diem Nguyen, Lena Thia, Deeba Ahmed, Jane Chudleigh, Joanne Miles, Lucy Brennan, Biarta Rhys-Jones, Alison Rowland, Robyn Hankins, Majella Maher and Bruce Whitehead for their help in recruitment and data collection.

Contributors SL and JS were responsible for the conception and design of this study; JS, AM-G, LMB and JM were responsible for supervision of studies within their respective laboratories; A-FH provided technical training, supervision and audit of data collection and analyses; AF-H, SL, JK, IdM, OS-P, JM and PC-E recruited the infants and undertook all data collection and analyses; SL collated all data from participating centres and together with VB and AW performed statistical analyses and modelling; SL, GD and JS drafted the manuscript; all remaining authors revised and approved the manuscript before submission.

Funding This study is supported by grants from the Dunhill Medical Trust, UK; British Lung Foundation; Cystic Fibrosis Trust; Special Trustees: Great Ormond Street Hospital for Children NHS Foundation Trust, London, UK; Smiths Medical Ltd, UK; Hunter Medical Research Institute, Newcastle, Australia; Hunter Children's Research Foundation, Newcastle, Australia and the Spanish team had a non-restricted grant from AbbVie.

Competing interests None declared.

Ethics approval London studies: East London and the City Health Authority Research Ethics Committee (REC) (P/97/250); UCL Institute of Child Health/Great Ormond Street Hospital REC (96EB23; 05/Q0508/141); North Thames Multi-centre REC (09/H071/314); Australian study: Hunter New England Health Human REC/09/ 07/15/5.04); Barcelona-Donostia study: Hospital Donostia: "Comité Ético de Investigación Clínica del Área Sanitaria de Gipuzkoa". Approval date: 22 September 2010; Hospital Vall d'Hebron: "Comité Ético de Investigación Clínica del Hospital Universitario Vall d'Hebron". Approval date: 14 September 2010; Lisbon study: Lisbon REC (Approval date: December 2005).

Provenance and peer review Not commissioned; externally peer reviewed.

\section{REFERENCES}

1 Turner DJ, Stick SM, Lesouef KL, et al. A new technique to generate and assess forced expiration from raised lung volume in infants. Am J Respir Crit Care Med 1995; 151:1441-50

2 Feher A, Castile R, Kisling J, et al. Flow limitation in normal infants: a new method for forced expiratory maneuvers from raised lung volumes. J Appl Physiol (1985) 1996;80:2019-25.

3 Ranganathan SC, Stocks J, Dezateux C, et al. The evolution of airway function in early childhood following clinical diagnosis of cystic fibrosis. Am J Respir Crit Care Med 2004;169:928-33.

4 Lum S,Gustafsson P, Ljungberg $\mathrm{H}$, et al. Early detection of cystic fibrosis lung disease: multiple-breath washout versus raised volume tests. Thorax 2007;62:341-7.

5 Borrego LM, Stocks J, Leiria-Pinto $P$, et al. Lung function and clinical risk factors for asthma in infants and young children with recurrent wheeze. Thorax 2009:64:203-9.

6 Filbrun AG, Popova AP, Linn MJ, et al. Longitudinal measures of lung function in infants with bronchopulmonary dysplasia. Pediatr Pulmonol 2011;46:369-75.

7 Pillarisetti $\mathrm{N}$, Williamson $\mathrm{E}$, Linnane $\mathrm{B}$, et al. Infection, inflammation, and lung function decline in infants with cystic fibrosis. Am J Respir Crit Care Med 2011;184:75-81.

8 Hoo AF, Gupta A, Lum $\mathrm{S}$, et al. Impact of ethnicity and extreme prematurity on infant pulmonary function. Pediatr Pulmonol 2014;49:679-87.
9 Jones $M$, Castile $R$, Davis $S$, et al. Forced expiratory flows and volumes in infants. Normative data and lung growth. Am J Respir Crit Care Med 2000;161(2 Pt 1):353-9.

10 Peterson-Carmichael SL, Rosenfeld M, Ascher SB, et al. Survey of clinical infant lung function testing practices. Pediatr Pulmonol 2014;49:126-31.

11 Lum S, Hoo AF, Hulskamp G, et al. Potential misinterpretation of infant lung function unless prospective healthy controls are studied. Pediatr Pulmonol 2010:45:906-13.

12 Mattes J, Hankin R, Hilton J, et al. Frequent persistent wheeze in infancy may be associated with impaired FEV 0.5 and FVC values. Am J Respir Crit Care Med 2011;183:A1890.

13 Nguyen $T T$, Thia $L P, H_{00} A F$, et al. Evolution of lung function during the first year of life in newborn screened cystic fibrosis infants. Thorax 2014;69:910-17.

14 De Mir I, Sardon-Prado 0, Corcuera-Elosegui P, et al. Impaired lung function in "healthy" preterm infants: Interpretation using new equipment-specific reference equations. Eur Respir J 2014;44(Suppl 58):1151.

15 Dezateux C, Lum S, Hoo AF, et al. Low birth weight for gestation and airway function in infancy: exploring the fetal origins hypothesis. Thorax 2004;59:60-6.

16 Thia $L$, Hoo AF, Brennan $L$, et al. Stable lung function is maintained over 2 years in newborn screened (NBS) CF infants. Eur Respir J 2013;42(Suppl 57):1072s.

17 Hoo AF, Lum S, Mattes J, et al. Manual of infant lung function tests. London: UCL Discovery, 2014

18 American Thoracic Society; European Respiratory Society. ATS/ERS statement: raised volume forced expirations in infants: guidelines for current practice. Am J Respir Crit Care Med 2005;172:1463-71.

19 Royston P, Altman DG. Regression using fractional polynomials of continuous covariates: parsimonious parametric modelling. App/ Stat 1994;43:429-67.

20 Cole TJ, Stanojevic S, Stocks J, et al. Age- and size-related reference ranges: a case study of spirometry through childhood and adulthood. Stat Med 2009;28:880-98.

21 Stanojevic S, Wade A, Cole TJ, et al. Spirometry Centile Charts for Young Caucasian Children: The Asthma UK Collaborative Initiative Am J Respir Crit Care Med 2009;180:547-52.

22 Cole TJ, Green PJ. Smoothing reference centile curves: the LMS method and penalized likelihood. Stat Med 1992;11:1305-19.

23 Rigby RA, Stasinopoulos DM. Generalised additive models for location, scale and shape. App/ Stat 2005;54(Part 3):507-54.

24 Schwarz GE. Estimating the dimension of a model. Ann Statist 1978:6:461-4.

25 Wright CM, Williams AF, Elliman D, et al. Using the new UK-WHO growth charts. BMJ 2010;340:c1140.

26 Kozlowska WJ, Bush A, Wade A, et al. Lung function from infancy to the preschool years after clinical diagnosis of cystic fibrosis. Am J Respir Crit Care Med 2008; 178:42-9.

27 Aurora P, Stanojevic S, Wade A, et al. Lung clearance index at 4 years predicts subsequent lung function in children with cystic fibrosis. Am J Respir Crit Care Med 2011;183:752-8

28 Quanjer PH, Stanojevic S, Cole TJ, et al. Multi-ethnic reference values for spirometry for the 3-95-yr age range: the global lung function 2012 equations. Eur Respir J 2012:40:1324-43.

29 ASH (Action on smoking and health). Annual Report 2014, ASH, 2014.

30 Hoo AF, Henschen M, Dezateux $C$, et al. Respiratory function among preterm infants whose mothers smoked during pregnancy. Am J Respir Crit Care Med 1998;158:700-5.

31 Pellegrino R, Viegi G, Brusasco V, et al. Interpretative strategies for lung function tests. Eur Respir J 2005;26:948-68.

32 Stanojevic S, Wade A, Stocks J. Reference values for lung function: past, present and future. Eur Respir J 2010;36:12-9.

33 Stocks J, Modi N, Tepper R. Need for healthy control subjects when assessing lung function in infants with respiratory disease. Am J Respir Crit Care Med 2010;182:1340-2. 